\title{
Reconsidering the lifetime deferral of blood donation by men who have sex with men
}

\author{
Mark A. Wainberg PhD, Talia Shuldiner BA, Karine Dahl MD, Norbert Gilmore PhD MD \\ Previously published at www.cmaj.ca
}

$\mathrm{T}$ he decision by blood agencies in many developed countries to defer the donation of blood by men who have sex with men was justified when it was first implemented, in 1983, given that there was no effective mechanism to screen for HIV infection until screening for HIV antibodies became available in 1985 . Thereafter, the exclusion of these men has continued, on the assumption that the higher seroprevalence of HIV in this group might lead to greater numbers of transfusion-related infections if blood screening were to fail. In 2010, many are asking whether all men who have had sex with men should still be excluded as blood donors or whether it might be possible to establish a defined deferral period for these men, based on the time of commencement of a new relationship.

Before Héma-Québec, the Canadian Blood Services and blood agencies in other countries accept blood, they ask prospective donors to complete a questionnaire about any potentially harmful behaviour and about the donors' medical history, including diseases, medical conditions, behaviours and drug use. ${ }^{1}$ In Canada, donations from people considered to be at higher risk for a transfusion-transmissible viral infection are permanently deferred. Reasons for permanent deferral include injection drug use, possible exposure to Creutzfeldt-Jakob disease, exchange of sex for money or drugs, and sex between men. ${ }^{2}$

The indefinite deferral of donation by men who have had sex with men prevents all such persons, even those in longterm monogamous relationships, from donating. In contrast, donors who have had heterosexual unprotected sex with multiple partners are not necessarily prevented from donating, provided the heterosexual donor claims to be aware of the sexual background of each of his or her sexual partners.

In Canada, if a heterosexual donor is not aware of the sexual background of each of his or her sexual partners, donation is deferred, but only for six months, a period that was recently reduced from one year. Several groups have challenged, before the courts, the ban against blood donation by men who have had sex with men, on the grounds that it is discriminatory and no longer has scientific rationale.

\section{History of the ban}

Between the late 1970s and the early 1980s, approximately 1200 Canadians became infected with HIV through blood transfusions. ${ }^{3}$ At that time, no tests were available that could detect HIV infection.

\section{Key points}

- As of 1983, in Canada and many other countries, blood donation has been deferred indefinitely for any man who has had sex with another man even once since 1977.

- In 1983, given the lack of scientific knowledge about HIV and AIDS, this approach was justified, because the prevalence of HIV among men who had sex with men was much higher than among most other individuals, and there was no blood test to screen donors for HIV infection.

- The current availability of highly sensitive methods to screen for HIV-positive samples argues against the maintenance of a lifetime ban for all men who have had sex with men.

In January 1983, the US Centers for Disease Control and Prevention held a public meeting ${ }^{4}$ at which a consensus was reached to implement the indefinite deferral of blood donation by men who had sex with men, because of suspicion that AIDS was a blood-borne disease and because the vast majority of all diagnosed cases of AIDS had occurred in homosexual men. ${ }^{5}$ In addition, any men who had had sex with men since 1977 were excluded, on the basis that this date would precede the start of the AIDS epidemic.

The Blood Transfusion Service of the Canadian Red Cross Society, the organization that was responsible for collecting, processing and distributing blood and blood products in Canada at the time, quickly moved to exclude members of high-risk groups, including men who had had sex with men and recent immigrants from what were considered to be highprevalence countries. In 1997, this policy was made more specific, and donations from any man who had had sex with a man even once since 1977 were refused indefinitely. ${ }^{4}$

Although a lifetime deferral of donations from men who have had sex with men has been implemented in other industrialized countries, such as the United States, France and Germany, some industrialized countries have shorter deferral periods: 1 year in Argentina, Australia, Japan, Hungary and Sweden; 5 years in South Africa; and 10 years in New Zealand. Elsewhere, deferral is discretionary, based on an individual's description of past sexual activity. ${ }^{6-8}$

From the McGill AIDS Centre (Wainberg, Shuldiner, Dahl) and the McGill University Health Centre (Gilmore), McGill University, Montréal, Que.; and the Lady Davis Institute (Wainberg), Jewish General Hospital, Montréal, Que.

CMAJ 2010. DOI:10.1503/cmaj.091476 


\section{The precautionary principle and the ban}

The precautionary principle is implemented in situations in which public health is in danger, and no conclusive scientific information is available. ${ }^{1}$ Under this principle, authorities responsible for public health may choose to act cautiously, without necessarily having robust scientific evidence on which to rely. ${ }^{8}$ However, the precautionary principle may be relied upon only to the extent that no new scientific evidence regarding the spread and origin of a disease becomes available. Otherwise, measures must be taken so that public resources are not expended on implementing an outdated policy. ${ }^{9}$

Many blood collection agencies and other groups worldwide have sought to have this deferral period shortened. In September 2004, for example, the HIV Medicine Association in the United States encouraged the US Food and Drug Administration (FDA) to re-evaluate blood donor criteria to reflect the availability of new testing procedures. ${ }^{10}$ In October 2004, Héma-Québec's Hemovigilance Committee was asked to consider a one-year deferral period for men who have sex with men, but the committee voted to maintain lifetime exclusion, on the grounds that there was insufficient evidence that these potential donors would not pose significant risk. ${ }^{11}$ In March 2006, the American Red Cross, America's Blood Centers and the American Association of Blood Banks unsuccessfully lobbied the FDA to implement a one-year deferral period. ${ }^{12}$

In Canada, as in most developed countries, men who have sex with men account for the largest subpopulation of HIVinfected people, i.e., $51.3 \%$ of the approximately 65000 infected persons in 2008 (Table 1). ${ }^{9}$ In 2005, the prevalence of HIV among men who have sex with men in Canada was estimated at $5.4 \%$, i.e., 67 -fold greater than the rate of $0.08 \%$ in the heterosexual population. Today, $76 \%$ of cumulative AIDS cases in Canada are thought to involve men who have had sex with men, which indicates that the proportion of people in this group who are infected, relative to all HIV-infected individuals, has grown. ${ }^{14}$ However, in Canada, more than $94 \%$ of men who have sex with men are not HIV-positive. ${ }^{1}$

Table 1: Subpopulations of HIV-infected people in Canada at the end of $2008^{*}$

\begin{tabular}{|c|c|}
\hline Subpopulation & $\begin{array}{l}\text { Estimated no. } \\
(\%) \text { infected }\end{array}$ \\
\hline Men who have sex with men & $31330 \quad(48.2)$ \\
\hline $\begin{array}{l}\text { Men who have sex with men who are } \\
\text { also injection drug users }\end{array}$ & 2030 \\
\hline Injection drug users & $11180(17.2)$ \\
\hline $\begin{array}{l}\text { Heterosexuals from nonendemic } \\
\text { countries }\end{array}$ & $10710(16.5)$ \\
\hline Heterosexuals from endemic countries & $9250 \quad(14.2)$ \\
\hline Others & $500 \quad(0.8)$ \\
\hline Total & $65000(100.0)$ \\
\hline
\end{tabular}

*Source of data: Public Health Agency of Canada. ${ }^{13}$

\section{Risks of allowing blood donation}

\section{Men who have sex with men}

One undeniable risk of allowing blood donation by men who have sex with men is a false-negative result on HIV testing, i.e., the occurrence of a negative result when the donor is, in fact, infected with HIV. This consideration applies to all prospective donors, including heterosexual people and other individuals, who may have been judged to be risk-free on the basis of an administered questionnaire.

With the development of more sensitive tests for detecting $\mathrm{HIV}$, the potential occurrence of a false-negative result is now remote, since the system no longer relies exclusively on the enzyme-linked immunosorption assay introduced in 1985 and the more accurate confirmatory Western blot test, also introduced in $1985 .{ }^{15}$ Now, highly sensitive nucleic acid testing is routinely used to screen blood. One participant in an FDA workshop held in March 2006 observed that "the probability that errors in routine screening will result in release of a unit [with hepatitis $\mathrm{C}$ virus or HIV] is so remote as to be inconsequential." 16

Although nucleic acid testing has greatly reduced the potential of false-negative results, there is still a possibility that a prospective donor has contracted a transfusion-transmissible viral infection but has not been infected for long enough for a test to detect its presence. This "window period" is often the most dangerous time for transmission, since the host may be unaware that he or she is carrying the virus and might unknowingly donate infected blood. ${ }^{17}$ With the advent of nucleic acid testing, ${ }^{18,19}$ the window period for detecting HIV has fallen to about 12 days from as long as 3-6 months when the system depended on antibody testing. ${ }^{19}$ Since Héma-Québec and the Canadian Blood Services implemented the recommendations of the Krever Commission, ${ }^{20}$ there have been no known transfusions of HIV-positive blood in Canada. ${ }^{21}$

Another concern is that gay men who believe they are in stable, long-term monogamous relationships could be deceived by their partners about the latter's monogamy. Although this concern cannot be discounted, it is just as relevant for both heterosexual donors and men who have sex with men.

\section{Women who have had sex with men who have sex with men}

For women who have had sex with a man who has had sex with another man, blood donation in Canada is deferred for one year after their last such encounter, whereas donation is deferred indefinitely for men who have had sex with men. In Quebec, allowing these women to donate (after the one-year deferral period) has been estimated to add 758 donors to the donor pool, an increase of $0.52 \% .{ }^{22}$ These women have the highest tolerated risk for blood contamination of all those now permitted to donate. ${ }^{1}$

\section{Benefits of allowing blood donation by men who have sex with men}

A major benefit of reducing the deferral period for men who have had sex with men would be enlargement of the donor pool. 
In 2003, Héma-Québec estimated that the total number of donations in Quebec would increase by $1.3 \%$ if the deferral period were reduced to one year. ${ }^{22}$ Allowing these men to donate after a one-year deferral period has been estimated to translate into a risk increment of only one HIV-positive unit escaping detection for every 11 million units of blood donated. ${ }^{22}$ In the United States, it has been estimated that a five-year deferral would lead to an increase of 71400 donors, whereas a one-year deferral would lead to an increase of 139000 donors. ${ }^{23}$

Blood agencies would also stop losing healthy donors who refuse to donate on the basis that the indefinite deferral of donations from men who have sex with men is discriminatory. For example, some student societies, universities and other organizations have stopped holding blood drives because of the indefinite deferral of men who have sex with men, ${ }^{24}$ which may also suggest to the public that the blood of all such men is diseased. A change in policy, based on scientific evidence, would remove this prejudice. A delicate balance must also be reached between the risk of contaminating the blood supply and the benefits associated with increasing the donor pool. ${ }^{5}$

\section{Other factors}

There are hypothetical concerns about novel, hitherto unrecognized infectious agents that might be transmissible through blood. The current focus is on HIV and hepatitis $\mathrm{C}$ virus because of the "tainted blood" scandals. However, the response to the potential transmission of West Nile virus has been efficient, with donor exclusion and nucleic acid testing having been implemented. ${ }^{25}$

With regard to the possibility that new blood-borne pathogens might emerge for which no diagnostic tests exist, the only precaution might be to defer blood donations from the populations most affected. ${ }^{26-28}$ Although the dissemination of blood-borne agents such as HIV and hepatitis $\mathrm{C}$ virus by men who have sex with men has been documented, a future unknown agent could potentially be preferentially transmitted by heterosexual rather than homosexual relations.

\section{Organ donation}

In December 2007, Health Canada changed its indefinite deferral to a five-year deferral period for organ donation by men who have had sex with men, in response to Canada's low rate of organ donation and the life-saving potential of such procedures. This decision seems to have been based on a consideration of relative risk and the supply and demand of available donors. Were the numbers of individuals willing to donate blood to diminish, there is little doubt that current restrictions on men who have had sex with men as blood donors would be relaxed.

\section{Individual behaviour}

Assuming no other risks that would lead to deferral, several factors can influence the risk posed by potential donors, such as the proper use of condoms during sexual intercourse and the number of different sex partners. Men who have sex with men who are in a long-term relationship with the same partner, for a year or longer, would be likely to have a very low rate of HIV infection and would pose a correspondingly low risk to the blood supply. ${ }^{19}$ The fact that these individuals are also far beyond the window period for HIV acquisition also decreases the uncertainty of undetected infection.

\section{Rapid testing and risk management}

Innovations in HIV testing, especially the increased availability of rapid testing, will result in more men who have sex with men being tested, learning their HIV status, reducing risky behaviour and receiving treatment earlier. This, in turn, would benefit blood safety - should men who have sex with men be allowed to donate - because they would learn about their HIV status and that of their partners through a mechanism outside the blood system. The risk can be measured in terms of the number of people potentially infected by donated blood relative to the total number of people who donate, ${ }^{4}$ zero risk is, of course, impossible to attain.

\section{Recommendations}

We believe that any potentially negative consequences of a change in deferral policy would be offset by benefits (Table 2). In fact, a five-year deferral period could maintain the same residual risk as indefinite deferral. In a 1992 study in the United States, $42 \%$ of the $9 \%$ of the total population who had ever had homosexual relations did not continue to do so past the age of 18. ${ }^{19}$ However, current policy dictates that donation by all of the men in this group is indefinitely deferred, regardless of whether their most recent encounter was last year or 30 years ago.

Table 2: Risks and benefits of a reduced deferral period versus indefinite deferral of blood donations from men who have sex with men

Risks Benefits

Reduce deferral period

(e.g., 1 or 5 yr)

- Possible refusal to receive blood transfusions because of fear of infection

- Increase in number of HIVpositive blood units collected

- Removal of a discriminatory policy

- Increase in number of eligible donors

- Possibility of accidental release of HIV-infected blood units because of false-negative results or organizational error

Maintain indefinite deferral

- Loss of potential healthy donors

- Unchanged risk of accidental release of contaminated blood units to the public

- Banning of blood drives in certain locations as protest against indefinite-deferral policy

- Unjeopardized prevention of transfusion of HIV-infected blood units

- Maintenance of a discriminatory policy 
The crucial questions are whether any increase in risk is allowable, and if so, on what basis? As noted above, changing to a one-year deferral would result in a risk increment of one unit of blood for every 11 million units collected, a small potential hazard to those receiving blood donations. ${ }^{22}$

A second option would be changing to a five-year deferral period. This alternative might be preferred, given that men who have had sex with men but without risky behaviour for five years or longer are not at greater risk of transmitting HIV infection than members of the general population. ${ }^{26-28} \mathrm{Ob}-$ viously, intermediate solutions, including deferral periods of two to four years, could also be entertained.

The current policy is counterproductive in terms of loss of donors, loss of good will, student protests, donor boycotts and lawsuits, among other negative effects. Notably, blood donation policy has already been changed to permit, as an example, donations from persons of Haitian origin, who were previously also subject to indefinite deferral. It's time for another change in policy.

In a case recently tried by the Superior Court of Justice (Ontario, Eastern Region), the Canadian Blood Services alleged that an individual misrepresented himself on the form that all blood donors are asked to complete. That individual has in turn countersued the blood agency for allegedly violating the Charter rights of men who have sex with men by asking the "discriminatory" question about whether they have had sex with a man since 1977. There is a strong possibility that the verdict in the case, due to be rendered in spring or summer 2010, may be challenged, regardless of the decision. It is important to understand that the verdict in this case may be different from that in other cases that are still in progress dealing with the much more straightforward question of whether men who have sex with men should be permitted to donate blood on a carefully defined basis, as opposed to maintenance of the lifetime ban against donation for all men who have had sex with men.

\section{This article has been peer reviewed.}

\section{Competing interests: None declared.}

Contributors: All authors were involved in drafting and revising the manuscript and in developing the concepts expressed therein. All authors approved the version for publication.

Acknowledgements: Research support in the authors' laboratories is provided by the Canadian Institutes of Health Research and the US National Institutes of Health.

\section{REFERENCES}

1. Leiss W, Tyshenkoa M, Krewskia D. Men having sex with men donor deferral risk assessment: an analysis using risk management principles. Transfus Med Rev 2008;22:35-57

2. Indefinite deferrals. Ottawa (ON): Canadian Blood Services; 2008. Available: www.bloodservices.ca/centreapps/internet/uw_v502_mainengine.nsf/page/Indefinite \%20Deferral?OpenDocument (accessed 2009 Oct. 6)

3. Harvey D. David, Goliath and HIV-infected blood. Can HIV/AIDS Policy Law Newslett 1996;2:2.

4. Stoto MA. The precautionary principal and emerging biological risks: lessons from swine flu and HIV in blood products. Public Health Rep 2002;117:546-53.

5. Gilmore N, Somerville MA. From trust to tragedy. HIV/AIDS and the Canadian blood system. In: Feldman E, Bayer R, editors. Blood feuds: AIDS, blood, and the politics of medical disaster. New York (NY): Oxford University Press; 1997. p. 127-60.
6. Germain M, Sher G. Men who have had sex with men and blood donation: Is it time to change our deferral criteria? J Int Assoc Physicians AIDS Care 2002;1:86-8.

7. Osmond DH, Pollack LM, Paul JP, et al. Changes in prevalence of HIV infection and sexual risk behavior in men who have sex with men in San Francisco: 19972002. Am J Public Health 2007;97:1677-83.

8. Hergon E, Moutel G, Duchange N, et al. Risk management in transfusions after the HIV blood contamination in France: the impact of the precautionary principal. Transfus Med Rev 2005;19:273-80.

9. Boulos D, Yan P, Schanzer D, et al. Estimates of HIV prevalence and incidence in Canada, 2005. Can Commun Dis Rep 2006;32:165-74.

10. HIV Medicine Association of the Infectious Diseases Society of America. Guidance for industry: eligibility determination for donors of human, cells, tissues, and cellular and tissue-based products. Correspondence to Division of Dockets Management, Food and Drug Administration (Docket 2004D-0193); 2004 Aug. 20. Available: www.fda.gov/ohrms/dockets/dailys/04/sep04/091404/04d-0193-ec2 -attach-1.pdf (accessed 2010 May 17).

11. CHS position on donor deferrals. Montréal (QC): Canadian Hemophilia Society; 2006 Mar. 31 [updated 2008 Feb. 12]. Available: www.hemophilia.ca/en/about-the -chs/public-affairs/chs-position-on-donor-deferrals/ (accessed 2010 May 17).

12. Kleinman S. Behavior-based blood donors deferral in the era of nucleic acid testing (NAT). Bethesda (MD): Blood Products Advisory Committee; 2005 Mar. 9. Available: www.fda.gov/ohrms/dockets/ac/06/slides/2006-4206S1_4a.htm (accessed 2010 May 17)

13. Public Health Agency of Canada, Centre for Communicable Diseases and Infection Control, Surveillance and Risk Assessment Division. Summary: estimates of HIV prevalence and incidence in Canada, 2008. Ottawa (ON): The Agency; 2008. Available: www.phac-aspc.gc.ca/aids-sida/publication/survreport/estimat08eng.php (accessed 2010 May 17).

14. AIDS in Canada. Toronto (ON): Canadian Foundation for AIDS Research; 2008 Available: www.canfar.ca/index.php?option=com_content\&task=view \&id=9 \&Itemi11en (accessed 2009 Oct. 7)

15. Branson BM. Point-of-care rapid tests for HIV antibodies. J Lab Med 2003;27: 288-95.

16. Busch MP. Residual risk of disease transmission by transfusion: causes and components. In: FDA workshop on behavior-based donor deferrals in the NAT era; 2006 Mar. 8; Bethesda (MD). US Department of Health and Human Services, Food and Drug Administration. Available: www.fda.gov/downloads/BiologicsBlood Vaccines/NewsEvents/WorkshopsMeetingsConferences/TranscriptsMinutes/UCM0 54430.pdf (accessed 2010 May 17).

17. Brenner BG, Roger M, Routy JP, et al. High rates of forward transmission events following acute/early HIV-1 infection. J Infect Dis 2007;195:951-9.

18. Busch MP, Glynn SA, Stramer SL, et al. A new strategy for estimating risks of transfusion - transmitted viral infections based on rates of detection of recently infected donors. Transfusion 2005;45:254-64.

19. Sanchez AM, Schreiber GB, Nass CC, et al. The impact of male-to-male sexual experience on risk profiles of blood donors. Transfusion 2005;45:404-13.

20. Krever H, commissioner. Final report: Commission of Inquiry on the Blood System in Canada. Ottawa (ON): The Commission; 1997.

21. Hochberg FA. HIV and blood donation policies: a comparative study of public health policies and individual rights norms. Duke J Comp Int Law 2007;12:231-54.

22. Germain M, Remis RS, Delage G. The risks and benefits of accepting men who have sex with men as blood donors. Transfusion 2003;43:25-33.

23. FDA workshop on behavior-based donor deferrals in the NAT era; 2006 Mar. 8; Bethesda (MD). US Department of Health and Human Services, Food and Drug Administration. Available www.fda.gov/downloads/BiologicsBloodVaccines /NewsEvents/WorkshopsMeetingsConferences/TranscriptsMinutes/UCM054430.pdf (accessed 2010 May 17).

24. Donny-Clark A, Rousseau MA. The blood drive debate. McGill Tribune 2007 Mar. 6. Available: http://media.www.mcgilltribune.com/media/storage/paper234 /news/2007/03/06/Opinion/The-Blood.Drive.Debate-2758370.shtml (accessed 2010 May 17).

25. Vamvakas EC, Kleinman S, Hume H, et al. The development of West Nile virus safety policies by Canadian Blood Services: guiding principles and a comparison between Canada and the United States of America. Transfus Med Rev 2006;20:97-109.

26. Vamvakas EC. Why are all men who have had sex with men even once since 1977 indefinitely deferred from donating blood? Transfusion 2009;49:1037-42.

27. Anderson SA, Yang H, Gallagher LM, et al. Quantitative estimate of the risks and benefits of possible alternative blood donor deferral strategies for men who have had sex with men. Transfusion 2009;49:1102-14.

28. Vamvakas EC. Scientific background on the risk engendered by reducing the lifetime blood donation deferral period for men who have sex with men. Transfus Med Rev 2009;23:85-102.

Correspondence to: Dr. Mark A. Wainberg, McGill University AIDS Centre, Lady Davis Institute, Jewish General Hospital, 3755 Côte Ste-Catherine Rd., Montréal QC H3T 1E2; mark.wainberg@mcgill.ca or Dr. Norbert Gilmore, Montreal Chest Institute (Room J8.02), Royal Victoria Hospital, McGill University Health Centre, 3650 St. Urbain St., Montréal QC H2X 2P4; Norbert.gilmore@mcgill.ca 